Pedagogía y Saberes No. 50

Universidad Pedagógica Nacional

Facultad de Educación. 2019. pp. 159-172

\title{
Educación mediática, institución cultural y nación. Entre el púlpito, el museo e internet*
}

\section{Artículo de investigación}

Media Education, Cultural Institution, and Nation. Between the Pulpit, the Museum and the Internet Educação midiática, instituição cultural e nação. Entre o púlpito, o museu e a Internet

Ancízar Narváez Montoya**

Para citar este artículo:

Narváez, A. (2019). Educación mediática, institución cultural y nación. Entre el púlpito, el museo e internet. Pedagogía y Saberes, 50, 159-172.

* Síntesis personal con base en el informe de final del proyecto Educación mediática y nación en Colombia: entre el púlpito e Internet, código DPG-437-16 del Centro de Investigaciones de la Universidad Pedagógica Nacional (CIUP), informe elaborado en coautoría con la profesora Ana Carmenza Romero Peña.

** Profesor titular de la Universidad Pedagógica Nacional. Doctor en Educación, magíster en Comunicación Educativa, licenciado en Ciencias Sociales. Investigador del grupo Educación superior, conocimiento y globalización.

Correo electrónico: anarvaez@pedagogica.edu.co - ancizarnarvaez@gmail.com Código oRCID: orcid.org/0000-0003-1429-3935 


\title{
Resumen
}

En este artículo de investigación se propone la educación mediática como la asunción de la cultura mediática, entendida como conjunto de códigos mediáticos y no como tecnología. Desde este punto de vista se analizan los mensajes producidos por cuatro instituciones nacionales que pretenden difundir un relato sobre la nación: la Iglesia, el Museo Nacional, el Salón Nacional de Artistas y dos medios periodísticos en internet. Los mensajes se analizan como piezas mediáticas en sus componentes de expresión y contenido y de sustancia y forma. Como estos relatos pretenden diferenciarse del relato académico, se consideran educación mediática, diferente a la educación escolar. Sin embargo, el resultado es contradictorio con las pretensiones.

\section{Palabras clave}

educación mediática; cultura; educomunicación; internet; teoría de los códigos

\begin{abstract}
In this research paper media education is proposed as the assumption of media culture, understood as a set of media codes and not as technology. From this point of view, we analyze the messages issued by four national institutions that aim to spread a story about the nation: the Church, the National Museum, the National Hall of Artists and two online news media. The messages are analyzed as media pieces in their components of expression and content, as well as form and substance. Since these stories aim to differentiate themselves from the academic narrative, they are considered to be mediatic education, which is different from school education. However, the results contradict the claims.
\end{abstract}

\section{Keywords}

media education; culture; educommunication; Internet; theory of codes

\section{Resumo}

Neste artigo de pesquisa, propõe-se a educação midiática como a assunção da cultura midiática, entendida como conjunto de códigos midiáticos e não como tecnologia. Deste ponto de vista, analisam-se as mensagens produzidas por quatro instituições nacionais que pretendem divulgar um relato sobre a nação: a Igreja, o Museu Nacional, a Sala Nacional de Artistas e as notícias de duas mídias jornalísticas na Internet. As mensagens são analisadas como peças de mídia em seus componentes de expressão e conteúdo, assim como de forma e substância. Dado que essas histórias procuram se diferenciar da história acadêmica, são consideradas educação midiática, diferente da educação escolar. No entanto, o resultado é contraditório com as pretensões.

\section{Palavras-chave}

educação midiática; cultura; educomunicação; Internet; teoria dos códigos 


\section{Introducción}

【 a relación entre comunicación y educación ha recibido muchos nombres: comunicación educativa, medios pedagógicos, enseñanza audiovisual, educación virtual, educomunicación, alfabetización mediática, etc., todos tan aleatorios como abigarrado es el campo (Morabes, 2008, p. 69). La incorporación de la cultura como elemento necesariamente asociado a ambas esferas no cambió sustancialmente las concepciones convencionales: la institucional y la versión tecnologista (técnicoeconómica), predominante en la llamada comunicación educativa.

La versión institucional presenta las tres nociones más o menos como tres categorías de igual nivel de abstracción y de igual grado de institucionalización, organizadas en tres sistemas (Parsons, 1964) a la manera funcionalista:

a. El sistema nacional de educación, regido por el Ministerio de Educación, encarnado en la escuela formal y sus diferentes niveles, cuya función es la instrucción y la inculcación (Bourdieu y Passeron, 2001), basada en saberes disciplinares o disciplinas escolares y cuyo estudio corre a cargo de la pedagogía y las ciencias de la educación.

b. El Sistema Nacional de Comunicación, regido por el Ministerio de las TIC (antes, Ministerio de Comunicaciones y, al principio, de Correos y Telégrafos, etc.) encarnado en el sistema nacional de telecomunicaciones (Telecom e Inravisión en su origen), basado en la transmisión de saberes comunes en forma de entretenimiento (ficcional) y de información (no ficción) o en la popularización de saberes disciplinares o artísticos a través de la adaptación mediática. Su estudio es el objeto de las ciencias de la comunicación, pero más exactamente de la mediología (Pireddu y Serra, 2014).

c. El sistema nacional de cultura, regido por el ministerio del mismo nombre, constituido por las instituciones artísticas y patrimoniales, cuya función es la formación del juicio estético para la fruición de las obras de arte y el patrimonio cultural, basado en el conocimiento estético del arte y el patrimonio legítimos, formalizado en la historia del arte y las humanidades.

En el campo de la educomunicación existe una vertiente que la entiende más como un movimiento social que como asunto teórico, por lo que se ha tendido a asimilarla con la comunicación alterna- tiva (Mateus y Quiroz, 2017; Mora, 2014; Morabes, 2008; Soares, 2000; Soares, 2014). Por otro lado, se suele presentar el debate como una dicotomía entre escuela y medios, entre educación presencial y virtual o entre interacción e interactividad. En este marco, se ha entendido la educación mediática como educación sobre los medios, por lo que siempre se ha tendido a confundir con alfabetización mediática. Asimismo, se ha entendido como educación por los medios, lo que ha hecho que se confunda con comunicación educativa o con los medios educativos.

En Colombia y América Latina [...], desde hace cerca de quince años, el campo se ha denominado de diversas formas: comunicación educativa, educomunicación, entre otras; sin embargo, nunca ha sido clara la relación de estos dos términos con la cultura, aunque implícitamente siempre ha estado presente y se ha entendido como cultura mediática o cultura escolar. (Muñoz, 2016, p. 9).

Pero estas versiones, aunque no dejan por fuera la cultura, no la consideran el primer nivel de abstracción sino una entre varias dimensiones. Aquí se pretende someter a discusión esas versiones para resignificarlas desde el punto de vista culturalista ${ }^{1}$. Para ello se propone entender la cultura, ya no implícita sino explícitamente, como una codificación de la realidad y, por tanto, las culturas como sistemas simbólicos (Narváez, 2013).

\section{Marco teórico}

\section{Educomunicación y educación mediática}

En el campo de la comunicación se ha venido construyendo un desplazamiento desde la llamada comunicación educativa a la educomunicación. Pero, al mismo tiempo, la educomunicación se ha entendido sucesivamente como movimiento social, confundiéndose así con una forma de comunicación alternativa, comunicación comunitaria, comunicación para el desarrollo, comunicación para el cambio social, etc. (Ángel y Obregón, 2011; Cadavid y Gomucio, 2014; Mora, 2014).

1 Para un panorama de la discusión en América Latina, que no es el objeto de este artículo, véase: Martín-Barbero (1980, 1996, 1999); Huergo y Fernández (2000); Valderrama (2000); Narváez (2004); Orozco (2004). Especialmente relevantes son los números monográficos de la revista Signo y Pensamiento, n.음 34, vol. XVIII, Bogotá, Pontificia Universidad Javeriana, 1999, primer semestre, y de la Revista Colombiana de Educación, n.o 46. Bogotá: Universidad Pedagógica Nacional-ciup, 2004, enero-junio. Para las síntesis más recientes: Mora (2014), Camargo (2015) y Muñoz (2016). 
En otra vertiente, la educomunicación se ha entendido como alfabetización mediática (Media Literacy); aunque la metáfora "alfabetización mediática" pudiera parecer cercana a la educación mediática, hay una diferencia sustancial: mientras que para esta versión la alfabetización mediática es sobre todo adiestramiento y aprestamiento en el manejo técnico de los medios (Koltay, 2011), para nosotros es competencia en el sentido del conocimiento de los códigos.

En esta presentación se propone: a) entender la educomunicación como la totalidad de la subjetivación humana, comprendida, a su vez, como la asunción de la cultura, de los códigos, en primer lugar, el lingüístico, y b) entender la educación mediática como una parte de la educomunicación, consistente en la asunción de la cultura mediática, comprendida, a su vez, como conjunto de códigos mediáticos y no como habilidades tecnológicas.

En efecto, la educomunicación que proponemos se entiende como proceso único e indivisible de enculturación, socialización y subjetivación, como asunción de los códigos de una cultura. En tal sentido, la educomunicación se realiza, no como la imbricación de tres funciones institucionales, sino como tres modalidades de esta: educación mediática, educación escolar y educación cotidiana.

Pero a diferencia de las modalidades institucionales, la educomunicación, en términos de códigos, se realiza más bien como educación icónico-narrativa (mediática), educación alfabética-argumentativa (escolar) y educación oral-ritual (cotidiana). Aquí entonces la cultura no juega como una instancia igual a las otras, sino que cada modalidad implica la difusión de una cultura como difusión de unos códigos. Es por no diferenciar tres instituciones (tres subsistemas de la sociedad) de tres tipos de códigos (tres sistemas de signos) que se cree que las instituciones llamadas culturales y educativas pueden transformarse en instituciones de "comunicación", entendidas como mediáticas, como si fuera posible la transposición de un código a otros y como si las otras instituciones no comunicaran cada una en sus códigos (Narváez, 2017)².

2 Este sería, a mi juicio, el motivo de la polémica, sobre el papel del Museo Nacional, que tuvo lugar en 2011 entre tres personajes (un académico, una artista y una directiva): la artista Beatriz González (2011), a mi juicio, está centrada en su papel como narración histórica; Cristina Lleras (2011), como funcionaria, estaría más interesada en el carácter mediático y por tanto en la publicidad del museo; el profesor Martín-Barbero (2011) reclama a su vez más amplitud tanto de la nación representada en la colección del museo como en el público al que debería dirigirse. Lo que se puede echar de menos en la polémica es que ello implica distintas narraciones y distintas codificaciones.

\section{Las instituciones como medios}

En el macroproyecto denominado Educación mediática y nación en Colombia, hemos pasado por el análisis de varios fenómenos en los que se articulan conceptos de diferentes disciplinas para abordar aspectos diversos de la comunicación en el país. Así, desde la economía política se aborda la formación del capitalismo y su relación con las telecomunicaciones, la industria cultural y el mercado cultural. Desde la sociología de los medios y la teoría de la mediación de los medios se ha enfocado el papel de los medios como instituciones (Martín, 1997). Desde la teoría de la recepción, con conceptos propios de la comunicología como la mediación en la recepción y las matrices culturales (Martín-Barbero, 2002) y especialmente con la teoría de los códigos (Eco, 1995), se ha tratado de entender a los medios como cultura. Así, se abordan los medios, no solo como institución, en lo cual compiten con la escuela, sino como narración, en lo cual compiten con el metarrelato ilustrado de la historia.

Entendemos la formación del Estado-nación como la asunción de dos narrativas occidentales: a) la universal (ecuménica) cuyo código de transmisión ha sido principalmente la escritura alfabética de la lengua sagrada latina y cuya institución legitimadora ha sido la Iglesia cristiana; b) la nacional, cuyo código de transmisión ha sido la escritura alfabética, también latina, pero de las lenguas nacionales modernas, y cuya institución legitimadora ha sido el Estado-nación (Narváez, 2013) como conjunto de instituciones que rigen una población en un territorio (Hobsbawm, 1998).

Las teorías clásicas de la comunicación han centrado sus análisis en los medios como instituciones (Curran, 2002; Hall, 1981; Maigret, 2005; Mattelart y Mattelart, 1998; McQuail, 1994; Merton y Lazarsfeld, 1992; Wolf, 1996); es decir, organizaciones que cumplen funciones en nombre de toda la sociedad (Castells, 1999) y representan un punto de vista autorizado. Una de esas funciones es producir un relato o una narración sobre la nación, una versión que puede ir de lo institucional a lo empresarial, pero que siempre es autorizada por el Estado, aunque sea una entre otras. En tal sentido, la narración que hagan de la nación se considera como legítima (Martín, 2009).

En nuestro caso, se trata de lo contrario. Tratamos las instituciones culturales y sus productos artísticos y patrimoniales como si fueran textos mediáticos en el sentido de que pretenden estar codificados a la manera mediática, es decir, como textos icónicos y propuestas narrativas. En tanto textos icónicos y narrativos dirigidos a la población, no importa si 
masiva o restringidamente, en señal abierta (broadcasting) o en línea (narrowcasting), tienen efectos educativos, no en el sentido de la instrucción (cognitivos) y la inculcación (éticos) o de la formación del gusto (estéticos) sino en el sentido de las formas de codificación; por tanto, se consideran educación mediática.

Por eso, también queremos proponer la comprensión de las instituciones tradicionales y nuevas como medios, es decir, como agentes que producen relatos sobre la nación en cualquiera de sus componentes: Estado, país, nación (instituciones, territorio, población) (Álvarez, 2010; Díaz, 2005; Morin, 1993). El relato de nación que realizan las instituciones a través de sus textos es lo que hemos tratado de explicar en el proyecto: educación mediática y nación en Colombia: entre el púlpito e internet.

El púlpito de la iglesia y los medios de internet constituyen los dos extremos de la institucionalización de las narrativas occidentales: la primera porque precede al Estado-nación y la última, porque, en teo- ría, lo supera. Entre ambas se encuentran dos instituciones encargadas de producir el relato nacional que, en la versión convencional, son el Museo Nacional y el Salón Nacional de Artistas, ambas adscritas al Ministerio de Cultura. Sin embargo, como se trata de los textos-discursos, no nos interesa tanto su carácter institucional como las características comunicacionales de los mensajes. En tal sentido, el estudio se hace desde la teoría de los códigos.

\section{Aspectos teórico-metodológicos. Teoría de los códigos}

En este apartado se trata no solo de hacer operativas las categorías que sirven de marco para el análisis comunicacional sino de explicitar los niveles de análisis y, por tanto, de abstracción, en los que se soporta la descripción de los productos mediáticos y que corresponden a la teoría de los códigos (véase la tabla 1).

\section{Tabla 1. Matriz de análisis comunicacional}

\begin{tabular}{|c|c|c|c|}
\hline \multicolumn{4}{|c|}{$\begin{array}{c}\text { Código } \\
\text { Función semiótica } \\
\text { Cultura } \\
\text { Mensaje }\end{array}$} \\
\hline \multicolumn{2}{|c|}{ Sintáctica } & \multicolumn{2}{|c|}{ Semántica } \\
\hline \multicolumn{2}{|c|}{ Expresión } & \multicolumn{2}{|c|}{ Contenido } \\
\hline Sustancia & Forma & Forma & Sustancia \\
\hline $\begin{array}{c}\text { Texto } \\
\text { Analógico/ } \\
\text { digital }\end{array}$ & $\begin{array}{c}\text { Figurativa/abstracta } \\
\text { Icónica/alfabética } \\
\text { Analógica/digital }\end{array}$ & $\begin{array}{c}\text { Figurativa/abstracta } \\
\text { Narrativa/argumentativa } \\
\text { (Sintagmática/ } \\
\text { paradigmática) } \\
\text { Sintética/analítica }\end{array}$ & $\begin{array}{c}\text { Discurso } \\
\text { Situacional/ } \\
\text { trascendental }\end{array}$ \\
\hline
\end{tabular}

Fuente: elaboración propia.

En el análisis comunicacional se asume que la cultura produce mensajes, como unidades sintácticosemánticas (además de pragmáticas) las cuales existen empíricamente como unidad indivisible de textodiscurso. A este modelo de análisis sobreponemos el modelo basado en la teoría de los códigos, el cual simplemente trata de complejizar un poco el anterior.

El primer nivel de abstracción lo constituye la categoría código como sistema simbólico y que es equivalente al sistema de signos o cultura, lo que en la terminología de Peirce (1987) se llamaría interpretante final, o sea, el sistema de signos dentro del que adquiere sentido cualquier signo.
El segundo nivel es el de la función semiótica, equivalente a lo que convencionalmente llamamos mensaje, que es producida por el código y no al revés. Es decir, la cultura no es una sumatoria de mensajes sino la norma o la regla que permite construir los mensajes; así mismo, la función semiótica es el producto del código.

El tercer nivel de análisis es el de los componentes del mensaje (sintáctico y semántico) o de los funtivos de la función semiótica (expresión y contenido).

El cuarto nivel de abstracción es el del análisis de los componentes de cada funtivo, por un lado, las formas y las sustancias de expresión y, por otro, 
las formas y las sustancias de contenido; la sustancia del contenido es el contenido manifiesto o explícito (discurso), mientras que la sustancia de la expresión (material) es el texto; las formas de expresión y las formas de contenido son las que permiten la correspondencia entre el texto y el discurso (mensaje). Cabe resaltar que en los textos artísticos hay una primacía de las sustancias expresivas sobre los demás componentes de la función semiótica, en cambio la sustancia de contenido es menos relevante; asimismo, la relación texto/discurso es más débil que en otros mensajes (Eco, 1995) como el académico, en el que sucede todo lo contrario.

El quinto nivel de abstracción es el análisis de las distintas sustancias expresivas (analógicas o digitales) y sus posibles subdivisiones, así como el análisis de las distintas sustancias de contenido (situacionales o trascendentales). También, es el análisis de las formas figurativas y abstractas tanto de expresión (sistema-código sintáctico) como de contenido (narrativas, géneros, etc.).

Estos cinco niveles de abstracción son comunes para cualquier tipo de mensaje o función semiótica producida en cualquier código o cultura. De ahí descendemos hacia formas analíticas distintas para cada tipo de mensaje. Como se ve en la tabla 2, para el arte es especialmente relevante la diferencia entre materiales tradicionales y no tradicionales (sustancia expresiva) o entre formas de representación (de contenido) como la exposición y las performances.

Se escoge como ejemplo la matriz correspondiente al análisis del Salón Nacional de Artistas porque tiene una complejidad intermedia para ilustrar las demás matrices (tabla 2).

Tabla 2. Matriz de análisis de las obras de arte

\begin{tabular}{|c|c|c|c|c|c|c|}
\hline \multicolumn{7}{|c|}{$\begin{array}{l}\text { Código (cultura) } \\
\text { Función semiótica (mensaje) }\end{array}$} \\
\hline \multicolumn{4}{|c|}{ Sintáctica } & \multicolumn{3}{|c|}{ Semántica } \\
\hline \multicolumn{4}{|c|}{ Expresión } & \multicolumn{3}{|c|}{ Contenido } \\
\hline \multicolumn{2}{|c|}{ Sustancia/texto } & \multicolumn{2}{|c|}{ Forma } & \multicolumn{2}{|c|}{ Forma } & $\begin{array}{l}\text { Sustancia/ } \\
\text { discurso }\end{array}$ \\
\hline Analógico & Digital & Figurativa & Abstracta & Abstracta & Figurativa & $\begin{array}{l}\text { Trascendental/ } \\
\text { situacional }\end{array}$ \\
\hline $\begin{array}{c}\text { Tradicionales } \\
22 \\
\text { Humana } 9 \\
\text { Natural } 7 \\
\text { Objetual } 32\end{array}$ & $\begin{array}{l}\text { Video } 4 \\
\text { Varios } 3\end{array}$ & $\begin{array}{c}\text { Dibujo } \\
\text { Pintura } \\
\text { Escultura } \\
\text { Arquitectura } \\
\text { (Maquetas) } \\
\text { Fotografía } \\
\text { Video Varios }\end{array}$ & & $\begin{array}{l}\text { Instalaciones } \\
39\end{array}$ & $\begin{array}{l}\text { Exposiciones } 29 \\
\text { Performances } 9\end{array}$ & $\begin{array}{l}\text { Destiempo } \\
\text { estado } \\
\text { Oculto } \\
\text { Uno como otro } \\
\text { Vorágine } \\
\text { La violencia } \\
\text { Saber y } \\
\text { desconocer }\end{array}$ \\
\hline Tradicional & No Tradicional & & & & & \\
\hline $\begin{array}{l}\text { Dibujo Pintura } \\
\text { Escultura } \\
\text { Arquitectura } \\
\text { Litografía } \\
\text { Fotografía } \\
\text { Bricolaje }\end{array}$ & $\begin{array}{c}\text { Humana } 9 \\
\text { Digital } 7 \\
\text { Objetual } 32 \\
\text { Natural } 7\end{array}$ & & & & & \\
\hline
\end{tabular}

Fuente: elaboración propia.

A partir de estas categorías se analizan los mensajes efectivamente producidos por cada institución, tales como: la puesta en escena de la liturgia (misa), la exposición permanente del Museo Nacional, el diseño de los portales de las páginas nacionales de internet más visitadas (Alexa Internet, 2016) y el catálogo de las obras presentadas en el 43 Salón (Inter) Nacional de Artistas. 
Luego se analiza el siguiente corpus: a) la Misa de dos parroquias comparables pero distintas por su importancia social, económica y mediática ${ }^{3}$, correspondiente al día 15 de mayo de 2016; b) dos salas del Museo Nacional, que narran la nación en dos periodos distintos: prehispánico (900 a. C.-1500 d. C.) y Emancipación y República, 1810-1886; c) la página inicial de los cinco portales nacionales de internet más visitados: Canal RCN, El Espectador, El Tiempo, Minuto 30 y Pulzo, correspondientes al 9 de octubre de 2016, aunque aquí se comparan solo dos, teniendo en cuenta el más antiguo y el más nuevo; finalmente, d) el catálogo de las obras presentadas en el 43 Salón Nacional de Artistas (último con información disponible).

Como se ve en la tabla 2, el análisis que proponemos no es ni cuantitativo ni cualitativo sino estructural. Esto merece una ligera explicación: el análisis estructural significa análisis de relaciones entre los elementos de una estructura, ya sea elemental (compuesta por pocos elementos y pocas relaciones) o compleja (muchos elementos y relaciones) (Greimas, 1987). En cualquier caso, no se necesita una muestra estadísticamente representativa de muchos mensajes, porque se supone que cada uno, incluso cada fragmento, puede representar la totalidad de la estructura, de la misma manera que en cada enunciado de la lengua está la estructura de la lengua; esto sugiere que se trata de análisis cualitativo. Sin embargo, la mayor o menor presencia de casos, de unas formas o sustancias en relación con otras, modifica la estructura, por lo que es necesario cuantificar estas ocurrencias para caracterizar los mensajes. Aun así, lo cuantitativo solo tiene importancia en la medida en que ayuda a precisar la cualidad interna del mensaje como totalidad, con lo cual se puede demostrar que un mensaje es predominantemente narrativo o argumentativo, situacional o trascendental, icónico o alfabético, etc., a pesar de que la apariencia pueda sugerir lo contrario.

\section{Iglesia, nación y narración}

Entre las instituciones que suelen configurar el arreglo institucional llamado Estado-nación, la Iglesia nacional no es de las menos importantes. Se diría

3 La diferencia social se debe a que es una parroquia más grande que abarca mayor población y más masiva asistencia; la económica, a la cantidad de recursos materiales que despliega, a la calidad de las instalaciones, etc; y la mediática al hecho de que una tiene transmisión por televisión siendo un espectáculo de más de una hora mientras que la otra se reduce al acto presencial. incluso que más que una institución o un aparato ideológico del Estado (Althusser, 2008), se erige como una contraparte del Estado, un contrapeso que lucha por alguna supremacía. De hecho, el gran debate que ha persistido sobre la formación del Estado-nación en Colombia es el de la relación IglesiaEstado. Los episodios son bien conocidos, desde la Conquista y la disputa sobre la humanidad o no de los indios, hasta la Constitución de 1991.

Para el análisis de la narración se grabaron y analizaron en sintagmas descriptivos dos misas en dos parroquias distintas por importancia social y mediática (Cristo Doliente y Jesús Amor Misericordioso), correspondientes al 15 de mayo de 2016. Aunque las grabaciones de las misas han sido realizadas por dos personas distintas, los dos lectores coinciden en el número de fragmentos, 23 y 24 respectivamente, lo cual habla de una secuencia rígida que no da cabida a nuevas o variadas unidades rituales. Coinciden, asimismo, el color rojo del traje del sacerdote y el color blanco del traje de los subordinados, lo cual muestra una disposición simbólica establecida, como corresponde a una representación ritual.

Por otra parte, hay unas coincidencias en la puesta en escena, técnicamente, forma del contenido, consistentes en la presentación de música y canto en vivo (en 8 y 9 secciones respectivamente) y en las alocuciones (intervenciones orales del sacerdote), cinco en cada caso. También, coinciden los sintagmas 6, 7 y 8 con el mismo contenido: lecturas, evangelio y homilía, o la relación que establece el sacerdote entre el texto religioso y la sociedad y la actualidad.

Las diferencias aparecen en el nivel de espectacularización de cada una de las puestas en escena, el cual se corresponde con la relación entre lecturas, alocuciones y otras representaciones escénicas. Como ya se dijo, las alocuciones parecen estar prescritas, entonces, el balance se establece entre las otras dos formas de representación: las lecturas y la escénica. En este aspecto, las proporciones son exactamente contrarias: en el primer caso (parroquia Cristo Doliente) las lecturas duplican a las escenificaciones o representaciones no previstas en el rito; en el segundo (parroquia Jesús Amor Misericordioso), estas duplican a las lecturas. Se trata evidentemente de mayores recursos materiales y de mayor disposición de personas para la escenificación, lo que hace que esta misa dure casi el doble de tiempo que la anterior.

En consonancia con lo anterior, las sustancias del contenido de la liturgia católica están fuertemente subordinadas a la forma prescrita por el ritual. Siendo 
cada sección una parte de la estructura formal de la narración, se espera que la estructura pueda ser llenada por un contenido más o menos libre en cada caso, en cada país o en cada parroquia, específicamente en la homilía, o la relación que establece el sacerdote entre el texto religioso y la sociedad y el momento en el cual se actualiza. Sin embargo, es sorprendente que los sintagmas en que se refieren aunque sea tangencialmente al contexto colombiano coincidan exactamente en las dos celebraciones: cinco en cada una $(8,10,12,18$ y 22 en un caso y 8 , $10,12,19$ y 22 en el otro). Esto indica también una prescripción casi a prueba de contexto de lo que se debe hablar.

En estos casos exactamente, el contenido de las partes centrales, el evangelio y la homilía, tenían que ver con lo que en el calendario litúrgico se llama el día de Pentecostés. Este, a su vez, se refiere a la idea del Espíritu Santo. Pero como hay una cierta tendencia católica al iconismo, la representación tiende a hacerse semejante en dos íconos (Peirce, 1987, p. 263): la imagen del fuego y la alegoría (metáfora) de la vida. Solo marginalmente se refiere a la paz, y a esta en sentido abstracto, sin ninguna referencia al proceso que se vive en Colombia en ese momento, en el que se negocia un acuerdo entre el Gobierno y la guerrilla de las FARC: "Pide también por la paz de nuestras naciones, especialmente por nuestra nación" (parroquia Cristo Doliente, sintagma 12); hay unas referencias marginales a Colombia, más como ilustraciones de los principios cristianos que se están reafirmando que como tema central de la alocución: "El sacerdote pide a Dios la concesión de la paz para vivir en gracia mientras llega la venida de Jesús" (parroquia Jesús Amor Misericordioso, sintagma 19).

El catolicismo parece estar por encima de las preocupaciones nacionales, pues se supone que el orden político en todo caso es temporal mientras que la Iglesia es trascendente: "En el espíritu Santo creaste al hombre para constituir un solo cuerpo, [...] unió a todas las lenguas en una sola fe" (parroquia Jesús Amor Misericordioso, sintagma 12). No hay, pues, diferencias nacionales. Así, la suerte del Estado y la nación no parecen estar en las preocupaciones de la Iglesia colombiana. Ha primado, en las celebraciones de la fiesta del Pentecostés, la narrativa universal sobre la particularidad nacional. Por consiguiente, se puede inferir que la versión que tiene la iglesia sobra la nación es que hay que formar buenos católicos antes que buenos colombianos y, por tanto, prima la formación de los feligreses de la iglesia sobre la de los ciudadanos del Estado.

\section{Museo, nación y narración}

Según Bellido, "los ideales republicanos propiciaron la fundación de estas instituciones consideradas útiles para la afirmación nacional" (2007, p. 17). Sin embargo, "el museo cambió entre los siglos XIX y $\mathrm{xx}$, cuando el eje de atención gira de las colecciones hacia el público" (Bellido, 2007, p. 27) o, en términos comunicacionales, del mensaje a la recepción. Por tanto, "actualmente el museo [...] ya no es solamente el lugar de acopio de los bienes culturales o el espacio reservado al estudio erudito del pasado" (Bellido, 2007 , p. 25), sino que su rol ahora es doble: promover el relato de la identidad nacional y a la vez ser parte de la economía local y, por tanto, debe hacer uso del espectáculo para convocar fuerzas sociales además de instruir a las personas.

Para ello, los museos tuvieron que hacer uso de los medios de comunicación para garantizar su papel institucional en la sociedad, pues

en una época dominada por la sociedad de consumo, los museos, querámoslo o no, forman parte de la amplia oferta de las industrias del ocio y el entretenimiento, y las estrategias de gestión deben tomar en cuenta esa variante para enfrentar el futuro de la institución como tal. (Bellido, 2007, p. 19).

Resumiendo, el museo como institución ya no es una prolongación o complemento de la educación escolar sino una parte de la educación mediática.

No obstante, la información recabada y el análisis particular de la sala Precolombina y la de la República, indica que el $100 \%$ y el $94 \%$ respectivamente de las piezas analizadas son alfabéticas o tienen respaldo informativo alfabético, lo que permite concluir que predominan las formas expresivas y de contenido abstractas en el Museo Nacional de Colombia, lo que exige que quienes lo visitan deben tener un conocimiento previo de las reglas de la cultura alfabética, las cuales se aprenden en la escuela a través del relato historiográfico oficial. Si un sujeto no cuenta con el aprendizaje del código alfabético, la mera observación de las imágenes, los documentos u objetos no le darán acceso a la significación de lo que allí se expone como memoria de la nación, pues esta se ha construido de manera alfabética y categorial. El museo carece por ahora de suficientes formas expresivas figurativas de tipo oral-icónico e interactivo y de formas de contenido narrativas, como relatos o dramaturgias, que permitan acceder al sentido de la muestra a personas no escolarizadas. 
En síntesis, el espectador debe tener conocimientos alfabéticos previos para comprender el significado de los objetos del museo (índices e iconos), o debe tener la disposición y la competencia para leer y comprender, in situ, los textos alfabéticos que los explican.

$¿$ Qué representa entonces el museo como medio de comunicación? Desde el punto de vista de las formas, representa la nación ilustrada que se narra por medios alfabéticos y un medio argumentativo, más cercano al relato escolar que al mediático. Por otro lado, es una sustancia de contenido de nación casi homogénea, heredera de la tradición hispánica pero no de la indígena, pues solo una de las trece salas está dedicada a la etapa precolombina, mientras que en la del siglo XIX, analizada en este caso, los indígenas y los afrodescendientes no aparecen, como si no hicieran parte de la nación (Rojas, 2001). Finalmente, es la nación institucional que se explica por los acontecimientos políticos (constituciones, presidentes, partidos, guerras, etc.), o sea la nación del Estado, tanto español como posterior a la independencia.

\section{Arte, nación y narración: Salón Nacional de Artistas}

Las exposiciones artísticas en Colombia fueron tomadas de la academia realista francesa del siglo XIX. El 28 de agosto de 1931 se inaugura el primer Salón Nacional de Artistas, el cual, años después, se formalizó como institución, dado el apoyo estatal y la frecuente participación y asistencia tanto de artistas como de espectadores. De ahí en adelante se organizaron distintas versiones.

La versión 43 del Salón Nacional de Artistas (Medellín, 2013) ha sido llamada (inter) Nacional como una manera de propiciar el diálogo con artistas y tendencias de carácter no necesariamente universal pero sí de otras naciones. El resultado ha sido que, a pesar de que los artistas nacionales son la mayoría de expositores (64 de 108), ha predominado lo internacional tanto en la expresión como en el contenido.

Para el análisis, proponemos una división de las sustancias expresivas identificadas específicamente en este Salón 43 entre tradicionales y no tradicionales (provisionalmente), teniendo como criterio que en las primeras es difícil escindir la sustancia de la forma, lo que conocemos como medios, y en las segundas, en cambio, los dos componentes son completamente independientes. En efecto, cuando entramos en las sustancias no tradicionales es más difícil establecer tales correspondencias. Si las dividimos en digitales, humanas, naturales y objetuales, podemos ver que no está claro qué clase de formas debe producir cada una de estas sustancias (tabla 2).
Humanas: el propio artista es parte de la obra. El artista interviene el espacio, ya sea como actor o incluso utilizando su cuerpo como soporte para ser intervenido de formas a veces dolorosas.

Objetuales: estas sustancias pueden ser de dos clases:

- Objetos artificiales: objetos ya elaborados que se utilizan como insumo para la construcción de la obra, dentro de la cual dichos objetos son resemantizados y refuncionalizados.

- Objetos naturales: resituados o, si se prefiere, recontextualizados, es decir, sacados de su medio natural y situados como parte de una obra de arte objetual, o sea de exhibición, pero no es técnicamente intervenido sino únicamente situado narrativa y conceptualmente dentro de la obra, como en la pieza 23 (instalación con fragmentos de plantas, motores, hilo y sensor).

Naturales: materias naturales usadas como insumo o materia prima para la elaboración de la obra. Estas son las más creativas, pues la materia tiene que ser intervenida artesanal y técnicamente, para darle alguna forma y convertirla en un objeto distinto al inicial. Así, por ejemplo, La cómoda es construida en paja y cáscaras de huevo (pieza 5, anexo 14) y La trampa, construida en bejuco de yaré (pieza 6, anexo 14). A diferencia de la anterior, la paja no representa la paja ni pasa a ser parte de una configuración con otros objetos sino que se convierte en cómoda, en otro objeto.

Es abrumador el predominio de las sustancias expresivas del tipo no tradicional, pues son predominantes en 55 de las 77 piezas examinadas. Dentro de ellas, las humanas todavía son minoritarias, dado que el hacer generalmente no se representa in situ y tampoco el narrar, sino como obras. En cambio el actuar, que exige la presencia del artista como parte de la obra, es más exigente. Por otro lado, el predominio de sustancias humanas y objetuales está dejando poco espacio para la intervención y transformación de materiales en obras, es decir, para el hacer. Esto plantea inquietudes sobre el arte contemporáneo, tales como esta: ¿Qué pasa con la habilidad técnica? ¿Qué distingue al artista de quien no lo es?

Las formas de contenido de las obras en este salón (inter) nacional de artistas oscilan entre dos tipos que llamaríamos ideales: por un lado, las formas tradicionales o exposiciones y, por otro, las más contemporáneas o performances. Y en el intermedio de estas, las instalaciones, al parecer la forma predominante del arte actual. 
Exposiciones. Podríamos llamarlas tradicionales por cuanto son las formas de presentación que se limitan a exhibir las obras para ser contempladas, percibidas e interpretadas por el espectador. Aquí el artista funge como creador en el sentido de hacedor, como quien interviene el material para convertirlo físicamente en otra cosa que antes no existía.

Performances. El artista funge como sustancia expresiva y protagonista principal de la obra. En contraste con la forma anterior, aquí el artista se presenta ya no como hacedor sino como actor, no solo en sentido dramatúrgico, como quien representa un papel en la obra, que también es el caso, sino como agente que actúa en la vida social extraartística, tomando parte o, mejor, proponiendo una actividad social que pretende influir en la realidad, pues "se entiende que si el arte moderno privilegiaba la creación de lo nuevo y las relaciones internas de su esfera, el contemporáneo encuentra su fuerza en las relaciones externas" (Mincultura, 2013c, p. 112).

Instalaciones. Intervención del espacio con diferentes objetos dispuestos para significar algo distinto a su contenido manifiesto, pero algo que no tiene norma que lo ligue a ese nuevo significado. Por tanto, el significado propuesto, no necesariamente leído, es completamente idiosincrático para el artista. Aquí el artista funge como creador, pero ya no en el sentido de hacedor (homo faber) sino en el sentido de pensador conceptual, como sugería Duchamp. "El conceptualismo [...] impone con gran éxito la arbitrariedad de que un objeto adquiera estatus de arte porque el artista le otorga un significado" (Lésper, 2016, p. 79).

Desde el punto de vista del contenido, el salón se divide en seis secciones, que hablan de temas trascendentales en general: destiempo, estado oculto, uno como otro, vorágine, la violencia y saber y desconocer.

De todas, la única que parece referirse explícitamente a Colombia es la titulada Violencia. Además, los títulos de las obras son casi tan explícitos como los de la sección: Sacrificio, La eterna primavera y los artistas del plomo, Atragantado, La vuelta 1, Madres ocultas y Prueba de vida. Paradójicamente, es la más pequeña, pues apenas incluye seis obras de las 77 que componen el total.

En otras secciones hay algunas obras que se refieren explícitamente a la situación contextual: Homenaje a Manuel Quintín Lame (pieza 7), Testigo (22 A y B), Cauca (24), Historia colonial del caucho (31), Tiempo medio (36), Minería (44), Dar la cara (24 paramilitares por segundo) (47), Any Comments o el instrumento delator (51), Arte y política, historia del Nadaísmo (52) y Visión remota (58). Son 11 obras dispersas en la exposición. En total, 17 obras sobre 77 , pero sin unidad narrativa.
Es significativo que las obras de la sección Violencia sean las más tradicionales en el sentido de las sustancias expresivas y también de las formas asociadas a ellas, pues aunque algunas son rotuladas como instalaciones, en realidad son cinco exposiciones: dos de fotografía, dos de video y una de escultura. La otra es un performance. Tanto las fotografías como las esculturas y los videos son completamente figurativas. 0 sea que la forma de la expresión es casi tan explícita como el contenido que pretenden transmitir. En tal sentido, lo más contextual es lo menos "artístico" del salón.

En conclusión, la lectura de este salón sugiere una tensión muy importante entre los artistas: moralmente compelidos a conectarse con la "realidad" del país, al mismo tiempo, se ven compelidos a inscribirse en las tendencias transnacionales del arte. Y las tendencias transnacionales hablan de varias cosas que superan la realidad interna: primero, del uso de materiales heterodoxos, es decir, de soportes, objetos, instrumentos, que en principio no están destinados a ser artísticos pero que tampoco son exclusivos del país; segundo, de la tendencia a la primacía de las puestas en escena de objetos (instalaciones) y de artistas (performances), las cuales son esencialmente efímeras, en detrimento de las obras perdurables y de sus exposiciones pasivas; y tercero, de los temas que tienen validez e importancia más allá de lo doméstico como el tiempo, lo desconocido, el ambiente, etc. Es decir, prima lo universal sobre lo contextual, pues, como en todas las gramáticas, para que haya "arte colombiano" primero tiene que ser "arte" y este es un reconocimiento que se da en el campo artístico, no en el contexto.

\section{Internet, nación y narración}

Como todos los fenómenos culturales occidentales, ya sean técnicos, éticos, políticos o estéticos, Internet es también una narrativa occidental que pretende ser universal y que se nacionaliza a través del mercado o de la institucionalización por el Estado.

Internet como tecnología hace parte de la historia de las telecomunicaciones. Su institucionalización tiene que ver con políticas de telecomunicaciones, no con políticas de comunicación y cultura. La diferencia para nuestro análisis radica en que el problema principal de las telecomunicaciones es el de la cobertura territorial, la cobertura poblacional, la estratificación, la regulación (pública o privada), mientras que la comunicación y la cultura tienen que ver principalmente con códigos y contenidos.

En consecuencia, nuestro análisis se basa en las organizaciones que utilizan esta plataforma tecnológica para su difusión. Escogimos entonces las cinco 
páginas informativas colombianas más visitadas (Alexa Internet, Inc., 2016) y de ellas hacemos la comparación entre dos representativas: un medio de información tradicional y su versión en línea y un medio que solo existe como diario en línea. El primero, El Tiempo, con más de 100 años de existencia; el segundo, Pulzo, con menos de una década.

Si hay alguna diferencia visible entre los llamados medios digitales y los tradicionales es la interactividad (Bettitini, 1995). Esta se puede considerar a la vez como una característica tecnológica (sustancia de la expresión) y una característica pragmática, como una forma de interacción. Pero entre una y otra existe una diferencia abismal, o sea que la una no implica la otra.

En efecto, la interactividad se entiende como la posibilidad de interactuar en tiempo real con el emisor o editor. Para ello consideramos tres niveles: a) pasiva, cuando solo ofrece la posibilidad de expandir la noticia por medio de enlaces, pero sin interlocutar con el emisor; b) activa, cuando permite responder, hacer comentarios, etc., que se vean reflejados en la propia emisión o edición; y c) interactiva, cuando el receptor puede intervenir en la elaboración de la información, editando, corrigiendo, etc.

Los resultados son desalentadores, dado que el medio más tradicional parece más interactivo que el más contemporáneo, pues la pasividad llega al 75\% y al $90 \%$ respectivamente, siendo las dos cifras bastante alejadas de lo que se espera de un medio digital. Por tanto, la presentación formal del texto no difiere mucho entre la sustancia electrónica y la sustancia química (papel) y tampoco entre la presentación electrónica de un medio tradicional y un medio digital.

Las sustancias expresivas representadas por las tecnologías digitales permiten elaborar gráficamente muchos contenidos no figurativos en formas distintas a la fotografía tradicional. Sin embargo, en esto no hay mucho cambio respecto a los medios analógicos y tampoco muchas diferencias entre los dos medios comparados, pues la gran mayoría de recursos icónicos son fotografías (70\% y $90 \%$ respectivamente). No se utiliza la tecnología por ejemplo para dibujos, diagramas y mucho menos para animaciones.

En cuanto a la forma del contenido, el medio que viene de la tradición utiliza cinco géneros distintos en solo 21 piezas informativas, mientras que el medio de la innovación apenas sí utiliza tres géneros distintos en 42 piezas informativas. Cuantitativamente, en el medio típicamente digital se utiliza la noticia como género narrativo en nueve de cada diez noticias, mientras que en el medio trasplantado se utiliza el mismo género en menos de seis de cada diez.
Esto encierra una cierta paradoja: El Tiempo, que es heredero de la tradición, resulta más innovador en el tratamiento de la información en cuanto a las formas tanto de expresión como de contenido y, por tanto, más adaptado a las nuevas posibilidades tecnológicas, que el diario que se supone innovador por no tener tradición anterior a Internet.

En síntesis, el nuevo medio no representa novedad ni en los géneros, ni en las fuentes ni en los sectores que visibiliza. En consecuencia, desde el punto de vista del periodismo y la información como código y como narrativa no estamos avanzando. Incluso en algunos aspectos, como vimos respecto a la narración en forma de noticia, los medios digitales presentan cierto atraso.

Pero hay algunas diferencias relevantes en cuanto a la sustancia del contenido, pues la prioridad es en un caso la paz y en el otro la farándula. Las proporciones en uno y otro caso son las mismas: una de cada cuatro noticias en El Tiempo es sobre la paz y una de cada cuatro en Pulzo sobre farándula.

Aquí estamos ante un típico caso de narrativa mediática caracterizada por la diferencia entre la épica y la parábola (Martín Serrano, 1997). La primera, la que se ocupa de los temas trascendentales y, por decirlo así, abstractos, que no tienen que ver con la vida cotidiana sino con la sociedad en general. Estas serían las noticias sobre la paz, una gran decisión política, y lo internacional, también relacionada con la política, pues se trata sobre todo de asuntos entre Estados o entre empresas de economía de escala. En cambio, la parábola tiene que ver más con lo cotidiano, con lo personal, con el consumo individual, con los gustos. Pero, sobre todo, tiene que ver con lo que está fuera de la economía y la política, o sea con el tiempo libre y con el entretenimiento.

Tal vez se pueda inferir que ambos ven una nación homogénea: en el caso del diario más tradicional, más inclinado a los ciudadanos; en el caso del diario más reciente, más inclinado a los consumidores. Ninguno de los dos refleja la nación diversa, la de las identidades.

\section{A manera de síntesis}

Existe una tendencia a considerar la educomunicación como una relación entre escuela y medios de comunicación y, en consecuencia, a considerar la educación mediática como el uso de medios o de TIC en la escuela.

Ya sea como tecnología (sustancia expresiva digital), como codificación (forma expresiva icónica), como relato (forma de contenido narrativa) o como 
discurso (sustancia de contenido situacional), la cultura mediática se considera "mejor" que la cultura escolar (regida por el Ministerio de Educación) o que la cultura artístico-patrimonial (regida por el Ministerio de Cultura). Esto hallevado a que las instituciones tradicionales como la Iglesia, el Museo Nacional, el Salón Nacional de Artistas y el diario impreso y alfabético, traten de asumir la lógica mediática y tecnológica.

Este proceso se lleva a cabo de manera desigual. En unos casos, como el de El Tiempo y el de Pulzo, llegando a internet, o sea, cambiando la sustancia de la expresión analógica por la digital electrónica. En otros, como el de la iglesia, minimizando el papel de la lectura de los textos sagrados (escrituras) y pasando a una sobreescenificación (oral y ritual) de la misa, o sea, modificando la forma expresiva y la forma de contenido. En el caso del salón de artistas, dando más protagonismo a las performances e instalaciones que a las exposiciones, o sea, cambiando la forma del contenido y, además, cambiando los materiales e instrumentos tradicionales por materiales "no artísticos" - objetos naturales o artificiales y personas-, es decir, cambiando la sustancia expresiva y pasando de lo icónico a lo indicial (Peirce, 1987).

Todo ello tiene implicaciones: una institución pretende acercar al público a las sagradas escrituras, pero lo hacen escamoteando lo alfabético de su comunicación; las otras pretenden convertir el relato alfabético en otro realmente dramatúrgico e icónico, pero lo hacen a través principalmente de textos alfabéticos.

En efecto, el acto de comunicación llamado misa se basa en tres codificaciones contrarias a lo alfabético: la oralidad y el histrionismo de sacerdotes y ayudantes, así como de los asistentes en forma de alabadores; el relato de parábolas o anécdotas de la vida cotidiana y la lectura en voz alta de relatos de los evangelistas, después de los cuales viene la exhortación oral del sacerdote en forma de imperativos más que en forma de conceptos.

En contraste, todo lo que se pueda entender del significado de los significantes del museo está supeditado a dos condiciones: tener conocimientos previos para poder enmarcar temporal y conceptualmente los objetos, o dedicar más tiempo a los textos explicativos alfabéticos que dan contexto a los objetos, que a los objetos mismos. Así, pretendiendo hacer del museo, por lo menos del nacional, una experiencia narrativa e icónica, en realidad se refuerza el carácter alfabético e ilustrado del museo como texto.
Asimismo, a pesar de la pretensión no alfabética del arte, la significación para el espectador viene principalmente de los textos alfabéticos, incluyendo los que recitan los guías, puesto que el significado de las obras es muy arbitrario pero al mismo tiempo completamente hipocodificado, es decir, en el SNA, sin la ayuda alfabética, cualquier cosa puede significar cualquier cosa. Las obras son, como diría Eco (1995, p. 282), galaxias expresivas y nebulosas de contenido.

Siendo internet un recurso técnico que permitiría, aun a los medios alfabéticos o gráficos como los diarios, presentar una versión icónica y narrativa de las noticias, lo que vemos es una versión abrumadoramente alfabética de los acontecimientos, a veces con un pantallazo sobresaturado de títulos, con pocos o ningún subtítulo y menos con algún tratamiento gráfico del alfabeto (diseño o diagramación).

En una apretada síntesis, las instituciones que fungen como medios o pretenden educar mediáticamente, no logran desprenderse del predominio de la cultura escolar, tanto en sus formas expresivas como de contenido. En cambio la iglesia, que pretende expresamente llevar la sagrada escritura a su público, es la única institución cuyo mensaje es inequívocamente oral, ritual, dramatúrgico y narrativo, por tanto, el menos escolar y el más mediático.

Desde el punto de vista del contenido de nación (la población con sus características), la Iglesia la ve como parte de la feligresía cristiana universal, el Museo Nacional ve la nación casi exclusivamente como población hispánica ilustrada, el Salón Nacional de Artistas entiende la nación como sinónimo de violencia y los medios en línea la ven como institucionalidad y como mercado.

\section{Referencias}

43 Salón Inter Nacional de Artistas Saber Desconocer. Cultura al Aire. Recuperado de https://www.youtube. com/watch?v=sc8_4IsCs84

Alexa Internet, Inc. (2016). Recuperado de http://www. alexa.com/

Althusser, L. (2008). Ideología y aparatos ideológicos de Estado. En S. Zizek, Ideología un mapa de la cuestión. Buenos Aires: Fondo de Cultura Económica.

Álvarez, A. (2010). Formación de nación y educación. Bogotá: Siglo del Hombre.

Ángel, A. y Obregón, R. (2011). Un análisis crítico de las perspectivas de diálogo en la literatura sobre comunicación para el desarrollo y cambio social: abordajes y desafíos. Signo y Pensamiento, Xxx (58), 190-205. 
Bellido, M. (2007). Aprendiendo de Latinoamérica. El museo como protagonista. Gijón: Trea.

Bettetini, G. (1995). Tecnología y comunicación. En G. Bettetini y F. Colombo, Las nuevas tecnologías de la comunicación. Barcelona: Paidós.

Bourdieu, P. y Passeron, J. (2001). La reproducción. Elementos para una teoría del sistema de enseñanza. Barcelona: Editorial Popular.

Cadavid, A. y Gomucio, A. (2014). Pensar desde la experiencia. Comunicación participativa en el cambio social. Bogotá: CUMD.

Camargo, A. (Coord.) (2015). Educación y tecnologías de la información y la comunicación. Serie Cátedra Doctoral. Bogotá: Universidad Pedagógica Nacional.

Castells, M. (1999). La era de la información. México: Siglo XXI.

Curran, J. (2002). Media and Power. Londres y Nueva York: Routledge.

Díaz, C. (2005). El pueblo: de sujeto dado a sujeto político por construir. El caso de la Campaña de Cultura Aldeana en Colombia (1934-1936). Bogotá: Universidad Pedagógica Nacional.

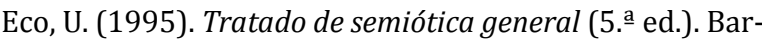
celona: Lumen.

González, B. (2011, mayo 24). La misión del museo no es permanecer lleno de gente, sino preservar la memoria del país. Entrevista en Arcadia. Recuperado de https:// www.revistaarcadia.com/arte/articulo/la-mision-delmuseo-no-permanecer-lleno-gente-sino-preservarmemoria-del-pais/25174.

Greimas, A. (1987) [1966]. Semántica estructural. Madrid: Gredos.

Hall, S. (1981). La cultura, los medios de comunicación y el "efecto ideológico". En Sociedad y comunicación de masas (pp. 357-392). México: Fondo de Cultura Económica.

Hobsbawm, E. (1998). Naciones y nacionalismo desde 1780. Barcelona: Crítica

Huergo, J. y Fernández, M. (2000). Cultura escolar, cultura mediática/Intersecciones. Bogotá: Universidad Pedagógica Nacional.

Koltay, T. (2011). The media and the literacies: Media literacy, information literacy, digital literacy. Media Culture \& Society, 33(2), 211-221. Recuperado de http://mcs. sagepub.com/cgi/content/abstract/33/2/211
Lazarsfeld, P. y Merton, R. (1993). Comunicación de masas, gustos populares y acción social organizada. En M. Moragas, Sociología de la comunicación de masas (pp. 22-49). Barcelona: Gustavo Gili.

Leroi-Gourhan, A. (1971) [1964]. El gesto y la palabra. Técnica y lenguaje. Caracas: Universidad Central de Venezuela.

Lésper, A. (2016). El fraude del arte contemporáneo. Bogotá: Libros Malpensante.

Lleras, C. (2011, mayo 24). Al museo de nada le sirve tener unas colecciones fantásticas si nadie lo visita". Entrevista en Arcadia. Recuperado de https://www. revistaarcadia.com/arte/articulo/al-museo-de-nadale-sirve-tener-unas-colecciones-fantasticas-si-nadielo-visita/25175

Maigret, E. (2005). Sociología de la comunicación y de los medios. Bogotá: Fondo de Cultura Económica.

Martín, M. (1997). La mediación de los medios. En J. MartínBarbero y A. Silva (comps.), Proyectar la comunicación. Bogotá: UNAL-Tercer Mundo.

Martín, M. (2009). La producción social de comunicación. Madrid: Alianza.

Martín-Barbero, J. (1980). Comunicación educativa y didáctica audiovisual. Cali: Sena.

Martín-Barbero, J. (1996). Heredando el futuro: pensar la educación desde la comunicación. Nómadas, 5, 10-22.

Martín-Barbero, J. (1999). La educación en el ecosistema comunicativo. Comunicar, 13.

Martín-Barbero, J. (2002). Oficio de cartógrafo: travesías latinoamericanas de la comunicación en la cultura. Bogotá: Fondo de Cultura Económica.

Martín-Barbero, J. (2011, agosto 22). El país que no cabe en el museo de doña Beatriz. Arcadia. Recuperado de https://www.revistaarcadia.com/impresa/articulo/ el-pais-no-cabe-museo-dona-beatriz/25905

Mateus, J. y Quiroz, M. (2017). Educommunication: A theoretical approach of studying media in school environments. Revista Latinoamericana de Ciencias de la Comunicación, 152-163.

McQuail, D. (1994). Introducción a la teoría de la comunicación de masas. Barcelona: Paidós.

Ministerio de Cultura. (2002). 38 Salón Nacional de Artistas. Cartagena de Indias Recuperado de https:// issuu.com/artesvisualesmincultura/docs/catlogo_38_ sna $/ 4 ? \mathrm{e}=13964509 / 11971029$ 
Ministerio de Cultura. (2013). 42 Salón Nacional de Artistas "Independientemente". Bogotá. Recuperado de http:// salonesdeartistas.com/node/140

Ministerio de Cultura. (2004). 39 Salón Nacional de Artistas. Recuperado de http://salonesdeartistas.com/ node/143

Mora, A. (Comp.) (2014). Comunicación educación un campo de resistencias. Bogotá: Corporación Universitaria Minuto de Dios. Facultad de Ciencias de la Comunicación.

Morabes, P. (2008). La investigación en comunicación/ educación: problemas epistemológicos y teóricos en la (in) definición del campo. Oficios Terrestres, 21, 68-79.

Morin, E. (1993). El Estado-nación. En G. Delanoi y P. A. Taguieff (comp.), Teorías del nacionalismo. Barcelona: Paidós.

Muñoz, G. (ed. acad.) (2016). Comunicación-educación para América Latina. Desafíos y nuevas comprensiones. Bogotá: Uniminuto.

Narváez, A. (2004). Cultura mediática y educación formal: un punto de vista comunicacional. Revista Colombiana de Educación, 46, 80-114.

Narváez, A. (2013). Educación y comunicación: del capitalismo informacional al capitalismo cultural. Bogotá: Fondo Editorial Universidad Pedagógica Nacional.

Narváez, A. (2015). Educomunicación y TiC: ni tecnologías de la comunicación ni para la educación. En A. Camargo (coord.), Educación y tecnologías de la información y la comunicación (pp. 199-218). Serie Cátedra Doctoral. Bogotá: Universidad Pedagógica Nacional.

Narváez, A. (2017). Comunicación educativa, educomunicación y educación mediática. Una propuesta de investigación y formación desde un enfoque culturalista. Palabra Clave. En proceso de publicación.
Orozco, G. (2004). Los museos interactivos como mediadores pedagógicos. Revista Colombiana de Educación, 46.

Parsons, T. (1964). The social system. Nueva York y Londres: The Free Press.

Peirce, C. (1987). Obra lógico-semiótica. Madrid: Taurus.

Pireddu, M. y Serra, M. (Eds.) (2014). Mediología. Cultura, tecnología y comunicación. Barcelona: Gedisa.

República de Colombia. Ministerio de Cultura. (2013a). Guía de lo desconocido. Bogotá.

República de Colombia. Ministerio de Cultura. (2013b). Libro de creencias. Bogotá.

República de Colombia. Ministerio de Cultura. (2013c). Catálogo de saber desconocer. Bogotá.

Revista Signo y Pensamiento, 34 (XVIII), Bogotá, Pontificia Universidad Javeriana, 1999, primer semestre.

Rojas, C. (2001). Civilización y violencia. La búsqueda de la identidad en la Colombia del siglo. Bogotá: Norma.

Soares, I. (2000). Educomunicaçao: um campo de mediações. Comunicação \& Educação, (19), 12 a 24.

Soares, I. (2014). Educomunicação e Educação Midiática: vertentes históricas de aproximação entre Comunicação e Educação. Comunicação \& Educação, XIX (2), 15-27.

Valderrama, C. (2000). Comunicación-educación. Coordenadas, abordajes, travesías. Bogotá: Universidad Central-Diuc.

Wolf, M. (1996). La investigación de la comunicación de masas. Barcelona: Paidós. 